\title{
César Calderón y Sebastián Lorenzo (coords.), Open Government. Gobierno abierto, Buenos Aires, Capital Intelectual, 2010
}

Facundo Cruz (Argentina) ${ }^{1}$

En los últimos años hemos sido testigos de un nuevo salto tecnológico con la rápida expansión de Internet y las oportunidades de comunicación que se generaron en torno a esta red mundial: las TIC (Technology of Information and Communications). La rápida aparición y crecimiento de estas herramientas ha generado cambios notables, no sólo en la forma a través de la cual las personas se vinculan y relacionan entre sí, sino incluso en las múltiples actividades que ellas mismas desarrollan.

Un particular impulso ha recibido el uso de TIC en el ámbito de la política en general, y de la administración del Estado en particular. Frente a este novedoso "avance revolucionario", existen, sin embargo, numerosos interrogantes y dudas sobre la forma, los medios, las estrategias y la profundización que se le debe dar a su implementación. Son precisamente estos interrogantes los que busca responder el libro Open Government. Gobierno abierto, coordinado por César Calderón y Sebastián Lorenzo.

La obra es un esfuerzo conjunto de varios y muy destacados analistas, escritores y pensadores españoles y argentinos, especialistas en distintas temáticas. A lo largo de ella, se pueden encontrar varios artículos que combinan un serio intento de realizar los primeros aportes teóricos al estudio de las relaciones entre las TIC y la administración

Facundo Cruz es Licenciado en Gobierno y Relaciones Internacionales (UADE). Es Secretario de Redacción de Revista POSTData y se encuentra cursando la Maestría en Análisis, Derecho y Gestión Electoral (UNSAM). 
pública, con numerosos ejemplos y casos de aplicación de estas herramientas en distintas administraciones.

Los artículos y ensayos coinciden en una serie de puntos clave, los cuales permiten analizar el concepto de Open Government desde una perspectiva más profunda, y no únicamente vinculado a la simple adopción de herramientas tecnológicas en la administración pública. En primer lugar, destacan que para comenzar a articular una estrategia de implementación de TIC en el Estado, el ciudadano debe pasar a ocupar el centro de atención. Como premisa básica, los autores coinciden en: 1) si el Estado debe ser el principal proveedor de bienes y servicios públicos, y 2) si lo que se busca es mejorar esa provisión, entonces el foco de todo el accionar estatal debe estar centrado en el ciudadano.

En segundo lugar, y como consecuencia de lo anterior, con este cambio de perspectiva se busca que a largo plazo se alcancen mayores niveles de transparencia en la administración de los asuntos públicos. Si la premisa es devolverles a los ciudadanos su rol preponderante, entonces un primer objetivo será construir un Estado más accesible y abierto para todos. Sin embargo, un Estado transparente no se logra "abriendo" todos los canales de información, sino que debe existir una selección, catalogación, categorización y un criterio de utilidad para brindar información a los ciudadanos, como bien aclara Pablo Díaz Cruz en su artículo.

En tercer lugar, en la perspectiva de estos autores, un Estado más transparente es la antesala para un segundo objetivo: lograr un mayor grado de participación ciudadana en los asuntos públicos. Si bien una estrategia de gobierno abierto sólo resuelve una parte del problema (esto es, poner a disposición información que resulte útil), la mayoría de los artículos coinciden en que brindar la posibilidad de acceder a esos datos generará los incentivos adecuados 
para un mayor involucramiento de los ciudadanos en la administración de los asuntos públicos.

En cuarto lugar, mayor apertura al ciudadano, transparencia y participación en la gestión pública se combinan para lograr mayores niveles de accountability. Como bien desarrolla Juan Manuel Abal Medina, implementar una estrategia seria de Open Government podría revertir el descrédito en el que se encuentran la mayoría de las instituciones públicas en la actualidad y devolverles así mayores grados de confianza ciudadana.

En pos de estos objetivos, varios son los autores que esbozan decálogos con lineamientos generales que especifican una serie de pasos a seguir para poder lograr los objetivos antes mencionados. Dos buenos ejemplos de ello pueden encontrarse en los artículos de Javier Linares y Antonio Manchado.

En una dirección similar, también pueden encontrarse a lo largo de la obra análisis más profundos y detallados sobre las potenciales ventajas que puede tener la adopción de estrategias de Open Government en áreas específicas de la administración pública. Por ejemplo, se destaca el abordaje que realiza el embajador español Rafael Estrella sobre las consecuencias y ventajas que ha tenido (y puede llegar a tener) la "diplomacia abierta". En la misma sintonía se centra César Ramón Esteban al analizar los potenciales beneficios que pueden obtener los partidos políticos si siguen un camino similar. Cabe también mencionar la interesante propuesta que realiza Juan Ignacio Belbis al estudiar, desde una serie de premisas teóricas, la posibilidad de avanzar en esa misma dirección en el ámbito legislativo, logrando mayores niveles de gobernanza y de participación ciudadana en la discusión de leyes.

Para poder lograrlo, resulta clave desde la perspectiva de los autores realizar un profundo y notable cambio cultural. No sólo en la ciudadanía, sino también (y más 
importante aun) en aquellos responsables de tomar las decisiones y de formular e implementar las políticas públicas. Es decir que para que los cambios sugeridos en la obra se puedan poner en marcha y se logre así modificar el paradigma imperante en la administración pública, es necesario cambiar valores, principios y normas culturales muy arraigados.

Sin embargo, los autores también coinciden en que se deben dar dos condiciones más para llegar a un "gobierno abierto y exitoso". Por un lado, resulta imperante abordar cuestiones de índole técnica, como es la reducción de la brecha digital y la adopción de plataformas de open source (como bien explica Martín Olivera). Por otro lado, es necesario que cierto liderazgo político se comprometa con la idea de que el Open Government mejorará a largo plazo la calidad de vida de los ciudadanos, y contagie esa convicción en la totalidad de la administración pública.

Es aquí donde la obra encuentra, tal vez, sus mayores limitaciones, pero que al mismo tiempo se convierten en oportunidades para lograr un cambio de paradigma en la administración pública, que es, en definitiva, la filosofía del Open Government. 